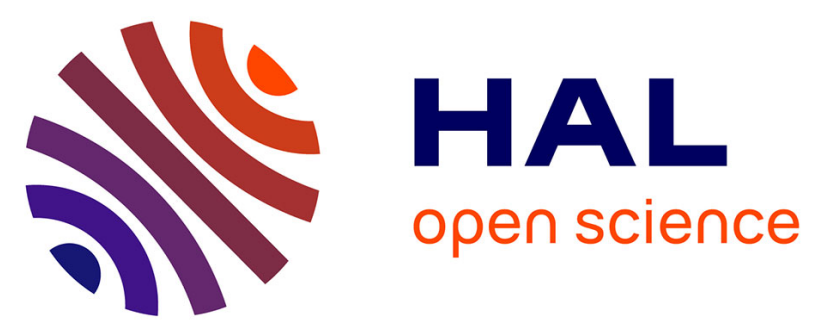

\title{
"Disorganized in time": Impact of bottom-up and top-down negative emotion generation on memory formation among healthy and traumatized adolescents.
}

Bérengère Guillery-Girard, Patrice Clochon, Bénédicte Giffard, Armelle Viard, Pierre-Jean Egler, Jean-Marc Baleyte, Francis Eustache, Jacques Dayan

\section{To cite this version:}

Bérengère Guillery-Girard, Patrice Clochon, Bénédicte Giffard, Armelle Viard, Pierre-Jean Egler, et al.. "Disorganized in time": Impact of bottom-up and top-down negative emotion generation on memory formation among healthy and traumatized adolescents.. Journal of Physiology - Paris, 2013, 107 (4), pp.247-54. 10.1016/j.jphysparis.2013.03.004 . inserm-00875450

\section{HAL Id: inserm-00875450 https://www.hal.inserm.fr/inserm-00875450}

Submitted on 22 Oct 2013

HAL is a multi-disciplinary open access archive for the deposit and dissemination of scientific research documents, whether they are published or not. The documents may come from teaching and research institutions in France or abroad, or from public or private research centers.
L'archive ouverte pluridisciplinaire HAL, est destinée au dépôt et à la diffusion de documents scientifiques de niveau recherche, publiés ou non, émanant des établissements d'enseignement et de recherche français ou étrangers, des laboratoires publics ou privés. 


\section{Accepted Manuscript}

"Disorganized in time": impact of bottom-up and top-down negative emotion generation on memory formation among healthy and traumatized adolescents

Bérengère Guillery-Girard, Patrice Clochon, Bénédicte Giffard, Armelle Viard, Pierre-Jean Egler, Jean-Marc Baleyte, Francis Eustache, Jacques Dayan

PII: S0928-4257(13)00006-5

DOI: http://dx.doi.org/10.1016/j.jphysparis.2013.03.004

Reference: PHYSIO 543

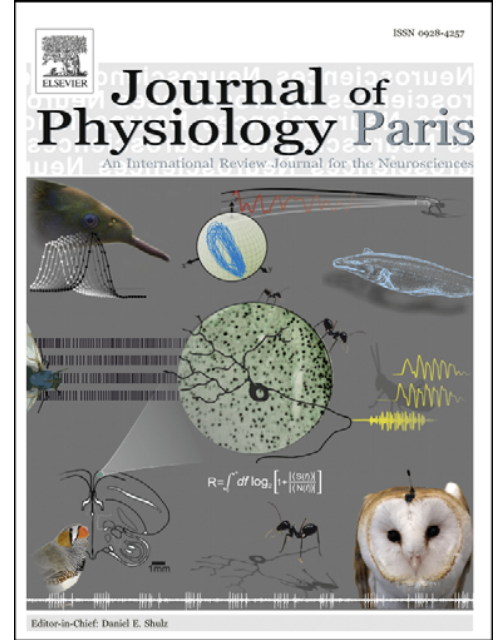

To appear in:

Journal of Physiology - Paris

Please cite this article as: Guillery-Girard, B., Clochon, P., Giffard, B., Viard, A., Egler, P-J., Baleyte, J-M., Eustache, F., Dayan, J., "Disorganized in time": impact of bottom-up and top-down negative emotion generation on memory formation among healthy and traumatized adolescents, Journal of Physiology - Paris (2013), doi: http://dx.doi.org/ 10.1016/j.jphysparis.2013.03.004

This is a PDF file of an unedited manuscript that has been accepted for publication. As a service to our customers we are providing this early version of the manuscript. The manuscript will undergo copyediting, typesetting, and review of the resulting proof before it is published in its final form. Please note that during the production process errors may be discovered which could affect the content, and all legal disclaimers that apply to the journal pertain. 


\section{"Disorganized in time": impact of bottom-up and top-down negative emotion generation on memory formation among healthy and traumatized adolescents.}

Bérengère Guillery-Girard ${ }^{\text {abcd }}$, Patrice Clochon ${ }^{\text {abcd }}$, Bénédicte Giffard ${ }^{\text {abcd }}$, Armelle Viard ${ }^{\text {abcd }}$, Pierre-Jean Egler $^{\text {abcde }}$, Jean-Marc Baleyte ${ }^{\text {abcde }}$, Francis Eustache $^{\text {abcd }}$ and Jacques Dayan $^{\text {abcdf* }}$

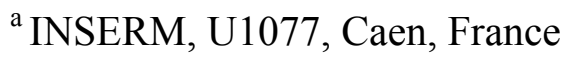

${ }^{\mathrm{b}}$ Université de Caen Basse-Normandie, UMR-S1077, Caen, France

${ }^{\mathrm{c}}$ Ecole Pratique des Hautes Etudes, UMR-S1077, Caen, France

${ }^{\mathrm{d}}$ CHU de Caen, UMR-S1077, Caen, France

${ }^{\text {e }}$ CHU de Caen, Service de Psychiatrie de l'Enfant et de 1'Adolescent, Caen, France

${ }^{\mathrm{f}}$ CHGR, Service Universitaire de Psychiatrie de l'Enfant et de l'Adolescent, Rennes 1, France

Keywords: time, attention, episodic memory, recollection, emotion, PTSD, adolescence

*Corresponding author: Inserm-EPHE-Université de Caen/Basse-Normandie, Unité U1077, Laboratoire de Neuropsychologie, CHU Côte de Nacre, 14033 Caen Cedex, France.

Phone: +33 (0)2 310651 97; Fax: +33 (0)2 310651 98. E-mail: jcdayan@gmail.com 


\section{Abstract}

"Travelling in time," a central feature of episodic memory is severely affected among individuals with Post Traumatic Stress Disorder (PTSD) with two opposite effects: vivid traumatic memories are unorganized in temporality (bottom-up processes), non traumatic personal memories tend to lack spatio-temporal details and false recognitions occur more frequently that in the general population (top-down processes). To test the effect of these two types of processes (i.e. bottom-up and top-down) on emotional memory, we conducted two studies in healthy and traumatized adolescents, a period of life in which vulnerability to emotion is particularly high. Using negative and neutral images selected from the international affective picture system (IAPS), stimuli were divided into perceptual images (emotion generated by perceptual details) and conceptual images (emotion generated by the general meaning of the material). Both categories of stimuli were then used, along with neutral pictures, in a memory task with two phases (encoding and recognition). In both populations, we reported a differential effect of the emotional material on encoding and recognition. Negative perceptual scenes induced an attentional capture effect during encoding and enhanced the recollective distinctiveness. Conversely, the encoding of conceptual scenes was similar to neutral ones, but the conceptual relatedness induced false memories at retrieval. However, among individuals with PTSD, two subgroups of patients were identified. The first subgroup processed the scenes faster than controls, except for the perceptual scenes, and obtained similar performances to controls in the recognition task. The second subgroup group desmonstrated an attentional deficit in the encoding task with no benefit from the distinctiveness associated with negative perceptual scenes on memory performances. These findings provide a new perspective on how negative emotional information may have opposite influences on memory in normal and traumatized individuals. It also gives clues to understand how intrusive memories and overgeneralization takes place in PTSD. 


\section{Introduction}

\subsection{Time and episodic memory in PTSD}

Episodic memory enables mental time travel in subjective time (Tulving 2002, 2005) and this "special, and unique relationship" of episodic memory to time, "surprisingly, is not widely known $[\ldots]$ allowing one to re-experience, through autonoetic awareness, one's own previous experiences" (Tulving, 1972). His statement has previously been expressed by H. G. Wells, in "The Time Machine" (1898) who writes: "You are wrong to say that we cannot move about in Time. For instance, if I am recalling an incident very vividly I go back to the instant of its occurrence: I become absent-minded, as you say. I jump back for a moment.” John Locke (1690/1975) has stated a long time ago that memory is the power "to revive perceptions, which it has once had, with this additional perception annexed to them, that it has had them before." Episodic memory is pivotal in autobiographical memory formed of different types of representations, from general knowledge about oneself (semantic component) to very specific personal events (Conway 2001). The way one remembers our past may be altered by selfconception (Wilson and Ross 2003) and reciprocally. Hence impairment in episodic memory of personal events may disrupt the sense of continuity and coherence of the self (Conway and Pleydell-Pearce, 2000). Episodic memory can be severely affected in individuals with PTSD with two opposite effects. Traumatic memories arise suddenly without any effort of recollection and even against one's effort to forget. These memories are unorganized in temporality and so vivid that the subject can feel he/she is actually reexperiencing the same event as the one that initially led to PTSD (bottom-up processes). Conversely, there is a trend to lose vividness and distinctiveness of other personal memories that become overgeneralized (top-down processes). 
Moreover, some clinical studies have shown that false memories (i.e., "memories" of personal facts that never happened) are more numerous in that population compared to healthy subjects (Brennen et al., 2007). Similarly, laboratory studies have shown that false recognitions are more frequent in PTSD compared to healthy subjects (Jelinek et al., 2009).

One of the main symptoms of PTSD is the intrusive recollection of highly specific single details of the traumatic event, criterion B of the definition of PTSD in DSM-IV-TR (American Psychiatric Association, 2000) with the patient acting or feeling as if the traumatic events were recurring. Temporality is severely altered in the sense that "what surges up in consciousness is not the memory of a "traumatic feeling" but a new feeling experienced in the present" (James, 1890). It initially takes the form of an unrelated set of sensory-perceptual details that only over time may come to be associated with a more abstract general event or lifetime period (van der Kolk and Fisler, 1995; Howe, 1997). According to Janet (1894) “traumatic memory" repeats the past, while "narrative memory" narrates the past as past. More recently, Brewin and collaborators suggest that memories of a personally experienced traumatic event can be stored in two different representational formats (Brewin et al., 1996; Hellawell and Brewin, 2004). One format consists of a memory available for verbal communication, which can be retrieved either automatically or using deliberate and strategic processes, i.e. top-down processes. The second format includes trauma-related dreams and "flashbacks" and emanates from low-level perceptual processing of the traumatic scene via sensory information that receives little conscious processing, i.e. bottom-up processes. Visual imagery is predominant in traumatic memories, although other sensory-perceptual details may be the first trigger. They are commonly associated with intense personal distress. A patient has written that "fragments of horrific experiences are captured in the "brain's eye". ... Those pictures ... are frozen in time. On any given day ...the pictures come to life again - the horror of what happened is once again very real, and it is 
happening all over again". A young child with PTSD came to our consultation asking us "to cure her eyes ... to wipe visions that was imposed to her”. A study using fMRI (Yang et al., 2004) indicated that patients with PTSD, compared to healthy subjects, both having experienced an earthquake, showed significantly greater activation in posterior visual (occipital) areas when evocating mental imagery about the trauma. Heightened proneness to form false memories in some specific laboratory tasks has also been shown (Jelinek et al., 2009) particularly with visual cues.

\subsection{Emotion and memory}

It is now well established that emotion influences memory formation (Buchanan, 2007). Most investigations have focused on how arousal (i.e., soothing or exciting effect of the stimulus) and valence (i.e., positive or negative) may interact with different processes, including attentional, perceptual, and conceptual processes (LaBar and Cabeza, 2006). Concerning explicit memory, there are two contrasting theories. The first proposes that emotion enhances recollective distinctiveness based on results showing that arousal increases memory vividness (Rimmele et al., 2011). Compared to words, perceptual stimuli, such as emotional pictures, seem more likely to elicit this recollection process. The second theory considers emotion as an organizational factor in memory that may enhance false memories related to the gist of the emotional target items. This conceptual relatedness hypothesis may be observed for both emotional words and pictures (Gallo et al., 2009). Although arousal is behind many significant changes in memory, from perception to consolidation (Mather and Sutherland, 2011), it has been clear for some time that the emotional valence of information also enhances memory, in a number of different ways. 
Behavioral studies have revealed that negative compared to neutral emotion, may enhance memory for specific details and leads to vivid recollection (Mickley and Kensinger, 2008). Nonetheless, negative emotional pictures may also increase confusability in memory and lead to false recollection (Gallo et al., 2009). This discrepancy suggests that some properties, specific to the pictures, may influence the recollection process.

More recently, two supplementary distinctions have been studied, perceptual versus conceptual processing, in addition to arousal and valence. These former types of processing refer to two distinct functional networks (Ritchey et al., 2011): processing perceptual emotional features relies particularly on an automatic pathway that includes the amygdale, while deep processing, focused on the meaning or interpretation of the emotional pictures, depends on prefrontal regions. These two distinct cortical networks overlap with those implicated in emotion generation: a bottom-up perception of aversive images and a top-down interpretation implicating conceptual understanding - including specific emotional state - of the emotional images (Ochsner et al., 2009).

Results on emotional memory in adolescence are in line with results in adult data showing a more pronounced memory bias for negative valence, for both hits (recognition) (d'Acremont and Van der Linden, 2007; Krauel et al., 2009) and false alarms (Nelson et al., 2003). Yet, neuroimaging studies have revealed that, unlike adults, adolescents are influenced more by the emotional nature of the stimuli than by the attentional demands of the task (Blakemore, 2008). Hare et al. (2008) have also reported that adolescents show exaggerated amygdala activity relative to children and adults during an emotional inhibition task. Wang et al. (2008) reported greater emotional interference in executive functioning in adolescents compared to adults when performing an emotional oddball paradigm featuring a human expression ( sad or neutral). The immature top-down control and an impaired regulation of emotion is often mentioned in the 
literature (Galvan, 2010). This cognitive control of affective networks, enabling the coordination between the executive and emotional systems, undergoes gradual maturation during adolescence (Yurgelun-Todd, 2007). Hence, bottom-up perceptual and top-down conceptual processes implicated in emotion generation may differentially affect memory, and adolescence constitutes an appropriate model to examine this question.

\subsection{Emotion and episodic memory in PTSD}

Most theories about emotional memory are also valid for memory in PTSD. However, they may be inefficient to explain all specificities of emotional memory in that population. Studies about emotional memory in PTSD have tried to explain the origin of intrusive memories, whether in the form of "flashbacks" or not. Fewer studies have investigated specificities of episodic memory according to the arousal and valence of the material to remember, notwithstanding items were not directly linked to the trauma. Contrasting results may be explained notably by activation of different brain networks according to the prevalence of bottom-up or top-down processes.

Different experimental designs have been used to study these different types of emotional memory. Concerning intrusive memories, according to fear conditioning models, PTSD is characterized by an exaggerated response of the amygdala to threat-related stimuli (St Jacques et al., 2011), hence of prevalent bottom-up processes. Less is known about the phenomenon of overgeneralization and false memories, particularly for emotional memories, which we will refer to as "numbing in time." Performance on declarative memory tests with neutral stimuli has been found to be consistently impaired in PTSD (Brewin et al., 
2007; Johnsen and Asbjornsen, 2008), although results are far more complex for emotional memories. Most studies found, among patients with PTSD, a threat-related memory bias characterized by a retrieval "advantage" for stimuli related to the trauma or for other specific threats compared to non-traumatic stimuli (Brewin, 2011; Golier et al., 2003). Hence, all types of visual or verbal materials that may be perceptively or semantically linked to the traumatic event may be differently encoded and recollected than any other material, even emotional. Additionally, this phenomenon can be accompanied by increasing false recognitions of verbal or pictorial negative material. This bias for trauma-specific stimuli is also observed in attentional tasks and may interfere with another concomitant processing, such as in the Stroop task (Yiend, 2010). Two mechanisms are traditionally evoked, although not contradictory: first a facilitated detection based on an over-reactivity to traumatic cues (vigilance-avoidance model) and, second, a difficulty disengaging attention from threatening stimuli (attention-maintenance model). However, two recent meta-analyses report inconsistent results (Cisler et al., 2011; Kimble, 2009) suggesting that only a part of the PTSD population demonstrates this bias. A third hypothesis may conciliate this apparent inconsistence focusing on the bottom-up and top-down attentional systems (Bardeen and Orcutt, 2011). High levels of stress may impair some aspects of the attentional control particularly those which are top-down regulated, especially inhibition processes (Pineles et al. (2007) and shifting, part of executive functioning. Hence, a prominent theoretical perspective proposed the top-down inhibition of the amygdala by the ventromedial prefrontal cortex as a major mechanism that may be defective in PTSD. Bardeen and Orcutt (2011) reported greater difficulty to disengage from traumatic stimuli for individuals with prominent symptoms of posttraumatic stress. We can speculate that this deficit in attentional control or top-down process may affect memory. 
Here, we examined this question by conducting two subsequent studies. The first study was conducted on a typical population of adolescents with the objective to assess top-down and bottom-up processes in emotion generation and their effect on attention and memory. This may enable us to validate our methodology and evaluate the "normal" influence of two different emotional processing: perceptual (or detailed-oriented) and conceptual (or based on the general meaning of the information). In the second study, we investigated these processes in patients with PTSD matched with controls, by distinguishing two subgroups, one with an attentional bias and another with no significant attentional interference, and their differential impact on memory. Two sets of negative emotional pictures were chosen from the internal affective picture system (IAPS; Lang et al., 2008) based on differences in subjective ratings relative to what induced the emotion, either perceptual details or a general interpretation of the scene. We studied both memory phases, i.e., encoding and explicit (recognition) retrieval.

\section{Method}

\subsection{Participants}

\subsubsection{Typically developing adolescents}

Sixty-four typically developing adolescents (39 girls and 25 boys) completed the tests. All the adolescents met the inclusion criteria: being free from neurological, psychiatric and learning disorders, as well as intellectual disability, receiving no medication and being native French speakers. We obtained informed consent from parents and assent from children, in line with the 
guidelines of the relevant ethics committees. They were recruited by means of invitation letters sent to several junior high schools in the Calvados (France). Mean age was $13.6 \pm 1.13$ years (163.4 \pm 13.6 months). There was no significant age difference between the boys and girls (boys: $164.64 \pm 13$ months; girls: $161.2 \pm 13.7$ months). Adolescents performed within the normal range on the Block Design $(11.2 \pm 2.5)$ and Vocabulary subtests $(11.8 \pm 2.9)$ of the Wechsler Intelligence Scale for Children (WISC-III; Wechsler, 1996), showing normal nonverbal reasoning and semantic knowledge.

\subsubsection{Adolescents with PTSD}

We compared 25 patients (age: $193.93 \pm 16.5$ ) to 24 healthy controls (age: $186.67 \pm 13.49$ ) matched on age $(\mathrm{p}=0.18)$. Inclusion criteria were similar to the first part of this study (see above). In particular, patients received no psychotropic medication during the previous week and were free from other mental disorders including major depression. The positive diagnosis of PTSD (categorical approach) was assessed with the Structured Clinical Interview-Clinician Version (SCID-CV; First et al., 1996) and the dimensional approach with the Impact of Event ScaleRevised (IES-R; Sundin ans Horowitz, 2002). All presented a chronic PTSD and were without traumatic stressor for at least one year. Patients were recruited through the University Hospital of Caen and from social centers of the departments of South Corsica, Northern area and Calvados (France). In order to explore the heterogeneity of performance in PTSD, we divided the group of patients in two, taking into account their performance on the neutral condition of the oddball paradigm (see Fig. 1 and 2). Thus, two subgroups of patients were identified: one subgroup with attentional performances significantly inferior to those of controls in the neutral conditions (PTSD-, $\mathrm{N}=12$, age: $190 \pm 20.47$ months) and another subgroup with similar or superior 
performances compared to controls (PTSD+, N=13, age: $197.53 \pm 11.42$ months). The two subgroups of patients did not differ significantly for the IES-R score $(p=0.3)$, scores on the Block Design $(\mathrm{p}=0.8)$ and Vocabulary subtests $(\mathrm{p}=0.53)$ of the Wechsler Intelligence Scale (WISC-III; Wechsler, 1996, WAIS III, Wechsler, 2000).

$$
+++ \text { Insert Fig } 1 \text { and } 2 \text { Here }+++
$$

\subsection{Material}

Three sets of photographs were selected from the IAPS (Lang et al., 2008): 36 neutral, 30 moderately negative qualified as "perceptual photographs" (i.e. emotion induced by perceptual details) and 30 moderately negative qualified as "conceptual photographs" '(i.e. emotion induced by the interpretation of the scene). The perceptual or conceptual nature of emotional pictures was previously tested among 20 students aged 20.25 to 23 years (mean age: $21.32 \pm 1.15$ years or $255.89 \pm 13.80$ months). For each picture, students had to indicate on a 9 point scale if emotion was induced either by specific perceptual details or by the interpretation of the scene $(1$ point $=$ mainly perceptual; 9 points = mainly interpretation). The perceptual photographs differed significantly from the conceptual ones (perceptual: $5.4 \pm 2.9$; conceptual: $6.8 \pm 2.4, \mathrm{p}<0.0001$ ). Although there was no difference in valence between the "perceptual" and "conceptual" photographs (semantic: $2.93 \pm 0.81$; perceptual: $2.60 \pm 0.86$ ), both sets of negative photographs differed from the neutral photographs (mean valence: $5.75 \pm 0.63 ; \mathrm{p}<0.001$ ). The latter had a low arousal level (mean: $3.70 \pm 0.83$ ) which did not differ significantly from the set of negative photographs, either conceptual $(5.21 \pm 0.99)$ or perceptual $(5.76 \pm 0.63)$. The neutral 
photographs showing peaceful animals, streets, unknown athletes and so on, did not overtly express any emotion. The perceptual emotional photographs featured injured or dangerous animals, car crashes and so on, while the conceptual emotional photographs contained scenes of crying or prostrated children/adolescents, portrayed adults wearing evil facial expressions or pretending to slap a child/adolescent.

We administered two visual tasks in order to test the effect of emotion on memory: an oddball paradigm intended to test attention, and a recognition task (Fig. 1). The oddball paradigm also constituted the incidental encoding phase for the subsequent test. Hence, the 32 photographs shown during this encoding phase also served as targets in the subsequent recognition memory task.

\subsection{Procedure}

The two tasks were constructed using E-Prime (Psychology Software Tools Inc., Pittsburgh, PA) which permits both item presentation and data collection (speed and/or accuracy). The Oddball paradigm featured four types of stimuli: 162 colored geometric figures $(83.5 \%$ of the items), 12 neutral photographs (6.3\%), 10 moderately negative perceptual photographs $(5.1 \%)$ and 10 moderately negative conceptual photographs (5.1\%). Stimulus duration was $1500 \mathrm{ms,}$ followed by an inter-stimulus interval of $2000 \mathrm{~ms}$ (gray screen for $1500 \mathrm{~ms}$ and fixation cross displayed in the center of a gray screen for 500ms). The interval between two successive photographs was randomized, although they were separated by at least five geometric figures. Participants were required to identify the images as quickly as possible, pressing on letter "L" of a keyboard with their right index for real scenes and letter " $\mathrm{S}$ " with their left index for geometric 
figures. Geometric figures constituted a reference condition, enabling us to register a motor response time $(\mathrm{RT})$.

We collected three RT ratios: negative perceptual, negative conceptual and neutral. Each ratio reflected the difference between the time taken to process the scenes and the time taken to process the geometric figures. The ratio was calculated as follows: (scenes - geometric figures) / geometric figures.

The recognition task assessed recollection abilities using the Remember/Know paradigm (Gardiner, 2001). Participants performed a yes/no recognition task, with keypress responses, featuring all the targets provided during the oddball, intermingled with new distractors. Each scene remained on the screen until the participant had either recognized or rejected an item. Each "yes" response triggered the display of a comic trip comprising three smileys representing "I remember", "I know", and "I guess" answers. Each type of response was carefully described, in order to ensure that the adolescents understood every concept. Thus, "I guess" would be chosen if they were not sure of their answer, while "I know" and "I remember" would be chosen when children were certain. However, while "I know" corresponded to the retrieval of a scene without any specific details about the encoded episode, "I remember" corresponded to the retrieval of a scene accompanied by a "mental journey back into the past," permitting the encoded episode to be relived and phenomenological details retrieved. Participants were required to indicate their responses using three different keypresses, one for each kind of consciousness. Unlike the oddball task, accuracy was the only constraint for the recognition task and the experimenter informed participants that there was no right or wrong answer for the consciousness task. This part of the test just provided an informative qualitative indicator of actual recognition. For this task, we calculated an accuracy score (Hits) for target and distractors and two scores reflecting recollection for every target correctly recognized that distinguishes between recollection 
(Remember responses / encoded associations; $\mathrm{R}$ ) and familiarity $(\mathrm{K} / 1-\mathrm{R}$, where $\mathrm{K}=$ Know responses / encoded associations).

\subsection{Statistical analyses}

\subsubsection{Typically developing adolescents}

Statistics were computed with SAS 9.1.3 Institute Software NPAR1WAY procedure. We conducted statistical analyses on typically developing adolescents. First, we verified the absence of age and gender effects by conducting two analyses: (1) an ANOVA on each measure, with gender as a between-subject factor and (2) a backward regression $(p=0.05)$ on the different measures, with age and $\mathrm{age}^{2}$ to test a nonlinear effect of age on performances. Second, we performed an ANOVA (generalized linear model; GLM) on the whole group with Tukey's adjustment for multiple comparisons (HSD) for each of the three tasks.

\subsubsection{Adolescents with PTSD}

Taking into account the small sample size of our population, we compared each subgroup of patients to controls by conducting non parametric analyses. We used Kruskal-Wallis test for multiple comparisons and Mann-Withney for two-sample t-tests, with the Monte Carlo permutation estimation of $p$ values. 


\section{Results}

\subsection{Oddball paradigm}

For the oddball task, analyses were performed on the three RT ratios: negative perceptual, negative conceptual and neutral.

\subsubsection{Typically developing adolescents}

For this task, nine participants were excluded from the analyses $(\mathrm{N}=55)$ : two because responses had not been recorded, one because performances were two standard deviations below the mean and six because they responded more slowly to geometric figures than to real scenes, perhaps revealing a declining concentration in the case of repeated geometric figure. The oneway ANOVA (emotion: negative perceptual, negative conceptual, and neutral) showed that emotion tended to affect response speeds $(F(2,106)=2.6 ; p=0.07)$. Adolescents tend to be slower for negative perceptual scenes (Fig. 2) compared to neutral scenes ( $\mathrm{p}=0.07)$, but not for conceptual scenes.

\subsubsection{Adolescents with PTSD}

Comparisons between controls and PTSD + revealed significant differences in response speed for neutral conceptual scenes $(\mathrm{p}=0.02)$ and negative conceptual scenes $(\mathrm{p}=0.03)$ : controls were slower than PTSD+ for these two kinds of scenes. There was no difference for negative perceptual scenes ( $\mathrm{p}=0.2$, Fig. 3). There was no effect of items for the PTSD $+(p=0.44)$. 
Comparisons between controls and PTSD- revealed significant differences for neutral $(\mathrm{p}<0.001)$, negative conceptual $(p=0.002)$ and negative perceptual scenes $(p<0.001)$. There was no effect of item for the PTSD- $(p=0.95)$.

$$
+++ \text { Insert Fig. } 3 \text { Here }+++
$$

\subsection{Recognition task}

\subsubsection{Typically developing adolescents}

For this task, six participants were excluded from the statistical analysis: data had not been recorded for four of them, while two others had performances below chance level. Results for the recognition task are shown on Table 1. The two-way ANOVA (status: target, distractor; emotion: negative conceptual, negative perceptual, neutral) performed on hits revealed a main effect of status $(\mathrm{F}(1,56)=6.33 ; \mathrm{p}=0.01)$ indicating that targets were better recognized than distractors. We also observed a main effect of emotion $(F(2,122)=13.65 ; \mathrm{p}<0.0001)$ : negative conceptual scenes generated the lowest performances compared to neutral scenes $(\mathrm{p}<0.001)$ and negative perceptual ones $(\mathrm{p}<0.0001)$. There was a significant interaction between status and valence $(\mathrm{F}(2$, $112)=22.66 ; \mathrm{p}<0.0001$ ), as negative conceptual controls were the least well categorized, i.e. correctly rejected.

The ANOVA on Recollection scores was not significant $(\mathrm{p}=0.1)$. However, negative perceptual scenes tended to be more closely associated with recollection than neutral scenes $(p=$ .08). No significant effect was observed for Familiarity scores. 


\subsubsection{Adolescents with PTSD}

Comparisons between PTSD+ and controls showed no significant differences between groups for any condition (Table 2a). A significant effect of emotion within the patient group appeared $(\mathrm{p}<0.001)$. Negative perceptual $(\mathrm{p}=0.003)$ and neutral distractors $(\mathrm{p}<0.0001)$ were better rejected than negative conceptual ones. Finally, negative conceptual scenes were better recognized as targets than as distracters $(\mathrm{p}=0.003)$. In contrast, neutral scenes were better recognized as distracters than as targets $(\mathrm{p}=0.05)$.

Comparisons between PTSD- and controls showed significant difference for negative perceptual targets $(\mathrm{p}=0.0351)$ and negative conceptual distractors $(\mathrm{p}=0.04)$. Patients recognized less negative perceptual targets and produced more false negative conceptual recognitions than controls. Within-group comparisons revealed a significant effect of emotion on distracters $(\mathrm{p}=0.013)$. Negative perceptual $(\mathrm{p}=0.01)$ and neutral distractors $(\mathrm{p}<0.0001)$ were better rejected than negative conceptual ones. Moreover, neutral distractors were better rejected than negative perceptual ones $(\mathrm{p}=0.04)$. Finally, negative conceptual scenes were better recognized as targets than as distracters $(\mathrm{p}=0.05)$. In contrast, neutral scenes were better recognized as distracters than as targets $(\mathrm{p}=0.003)$.

Concerning Recollection and Familiarity, significant differences between PTSD- and controls were detected for negative conceptual $(\mathrm{p}=0.02)$ and negative perceptual $(\mathrm{p}=0.05)$ scenes. Patients produced less recollective judgments than controls (Table 2b).

\section{Discussion}

The aim of the present study was to investigate the influence of bottom-up and top-down 
processes on memory in adolescents with PTSD. These two processes may participate, or even be central, to induce the opposite effects observed in episodic memory, i.e. vivid traumatic memories and an overgeneralization of non traumatic personal memories.

Until now, most studies have focused on valence and arousal properties of the information. Our results provide evidence of another essential dimension that needs to be considered in the general population and in PTSD, that is, the perceptual versus conceptual properties of the emotional stimulus. We tested the putative differential effects on memory both at encoding, by means of an attentional task (oddball paradigm), and at retrieval, using explicit (recognition) memory tasks.

\subsection{Attentional processing}

Concerning healthy adolescents' performances on the oddball paradigm, moderately negative perceptual scenes captured more attention at encoding than moderately negative conceptual scenes or neutral ones. This negative bias effect confirms previous studies showing that the perception of moderate emotions has an effect on memory. It is well documented that the attentional bias to negative information induces errors (Schimmack and Derryberry, 2005) or slows down the processing of a concomitant task (Algom et al., 2004), as in the present case (judgment of perceptual properties). The existence of this negative bias has been confirmed by electrophysiological studies, showing early attentional capture (Olofsson et al., Polich, 2008) and a long-lasting effect of negative emotion, persisting for approximately $1000 \mathrm{~ms}$ after picture offset (Hajcak and Olvet, 2008). It is unlikely that the attentional capture observed in the present study results from a difference in arousal between the negative perceptual and neutral scenes, as they 
are matched for arousal level. Consequently, it is the content of the scenes (i.e., the presence of the perceptual details) that produces interference effects. This phenomenon is concordant with the automatic vigilance hypothesis recently developed by Estes and Adelman (2008) in adults.

However, negative conceptual scenes did not affect attention to the same extent as negative perceptual items did. First, even if the global meaning of the conceptual scene may be largely threatening, details of the negative conceptual scenes by themselves are less directly threatening than those contained in the perceptual scenes (e.g., fangs in an open mouth of a reptile versus a man looking furious with a hand up). Second, attention is focused on the interpretation of the scene rather than on external aversive stimuli.

Concerning adolescents with PTSD, the different patterns reflect the clinical heterogeneity of PTSD patients (van der Kolk, 2006; Elhai, 2011). The first group of patients (PTSD+, faster than controls) is characterized by an accelerated cognitive processing suggesting that either they did not pay much attention to real scenes or they actively shift from the scenes, except for negative perceptual ones. The second group (PTSD-, slower than controls) shows an impairment of attention independently of the kind of stimulus (neutral or emotional): they have difficulties to disengage their attention from geometric figures to process real scenes. These results are unlikely due to general slowness because performances are expressed as ratios, excluding an interpretation based on low response speed for geometric figures. They probably have difficulties in switching which may be linked to inhibition processes. This hypothesis needs to be tested further with specific cognitive tasks.

\subsection{Explicit memory}


Concerning the patterns of performance obtained in the healthy group, we can conclude that the negative emotion generated by both the perceptual and conceptual properties of the pictures have opposite effects on explicit memory. The feeling of recollection or the vividness of negative traces is increased in the case of negative emotional perceptual memories compared to neutral ones, although their accuracy is comparable. As recently demonstrated by Rimmele et al. (2011), negative stimuli may increase subjective recollection with no effect on accuracy. This can be explained by the fact that these negative stimuli provoke an attentional capture and, thus, exert a significant positive effect on episodic memory, enhancing the recollection of item-specific features or local stimulus details. These results support the prediction of emotional enhancement of memory in the attention mediation hypothesis formulated by Talmi et al. (2008) related to the emotional distinctiveness heuristic hypothesis formulated by Schacter et al. (2007).

Negative emotion may also promote the production of false memories based on meaning similarities in particular conditions (Brainerd et al., 2008). This phenomenon supposes that emotion serves as an organizational factor in memory and may enhance false recognition comparable to the emotional gist of the target (Howe et al., 2010).

We show that the increase of distinctiveness or false memory may depend on the main qualities of the process of emotion generation, relying either on perceptual properties or on semantic qualities. Hence, focusing on general information or on the feeling induced by negative conceptual targets, create gist traces and subsequently an increased rate of false memories by leading to a confusion between the presented and unshown pictures. Brainerd et al. (2008) report a high level of false memories associated with negative emotion for verbal materials and attributed this phenomenon to the absence of verbatim memories or episodic details of true items. In the present study, the adolescents produced more false memories for negative conceptual distractors than for neutral ones. Moreover, these negative false memories are not associated with 
modifications in the recollection process, which only occur in case of negative perceptual memories.

Concerning patients, the heterogeneity observed during the oddball task leads to distinctive performances in explicit memory. In particular, patients with the lowest performances did not benefit from the distinctiveness associated with negative perceptual scenes to enhance memory performances. This can be linked to the fact that they demonstrated an attentional deficit that did not allow them to significantly encode these scenes. Emotion may also be less easily triggered by emotional cues, impairing the process of recollection. This state reflects what is also clinically described as "emotional numbing" which corresponds to an excess of overgeneralized memories. Several studies have also found evidence of overgeneral memory in PTSD (Moore and Zoellner, 2007) whose answers usually do not refer to a specific episode, precisely localized in time and space. Instead, they either refer to an extended or a vaguely defined period or describe habits or categories of events with quite broad descriptions. It has been hypothesized that overgeneral memories protect the patient from the unpleasant recall of painful or even traumatic events (Williams et al., 2007). Thus, contrary to intrusive recollection, events of the past tend to be recollected without emotionality or with low arousal. This trend clinically corresponds to part of the C criterion of PTSD, i.e. "numbing of general responsiveness" according to the DSM-IV-TR (American Psychiatric Association, 2000).

This is associated with an elevated level of false recognition for negative conceptual control stimuli that confirms results from other studies (Jelinek et al., 2009). Moreover, this result is only observed for conceptual scenes suggesting that difficulties in top-down control enable patients with attentional difficulties to reject conceptual scenes they have never seen. 


\section{Conclusions}

Taking into account the two present studies, emotion generation may affect memory through a continuous completion between a bottom-up approach which uses the perceptual features of the information and a top-down approach which uses general knowledge. Top-down processes or conceptual interpretation includes the observation of another person's emotional state that will activate our own representation of that state and/or a self-generated negative emotion. This process requires a great sensitivity to information, including emotion, and is crucial in the development of social understanding and positive social behaviors.

Our findings suggest a differential effect of top-down and bottom-up processes on memory in adolescent psychiatric disorders. The top-down control, which is immature during adolescence and impaired in PTSD, may have a role in the disorganization in time and, hence, in the sense of continuity and self -coherence. Traumatic memories have an impact on patients' daily life due to their intrusive nature. Here, we show that traumatic memories have also a permanent impact on the capacity to process efficiently daily emotional material when a conceptual interpretation is required. For instance, in the case of repeated negative experiences, enhancement of similarity judgments may increase the confusion between these different experiences which may prevent them from extracting the chronology of each individual personal event. Normally, details of a specific event are accessed via top-down processes in a forward temporal order, after the first details or sequences have been remembered (Burt et al., 1995). This confusion in time may favor a generalized distrust or hostility triggered by similar stimuli. Hence, the past may be considered as the present in PTSD with a specific but permanent interference on both personality and 
cognitive functioning. It would be interesting to examine, in further studies, the neural networks recruited by these top-down and bottom-up processes and the associated connectivity between the activated brain regions. 


\section{Acknowledgments}

This study was supported by the Caen school district and the Mutuelle Générale de l'Education Nationale mutual insurance company. We would like to thank Marion Nys for his assistance with collecting data. We are also indebted to the children, adolescents and institutions that took part in our research. 


\section{References}

Algom, D., Chajut, E., Lev, S., 2004. A rational look at the emotional Stroop phenomenon: A generic slowdown, not a Stroop effect. J Exp Psychol Gen. 133, 323-338.

American Psychiatric Association, 2000. Diagnostic and Statistical Manual of Mental Disorders (4th edn, text rev.). American Psychiatric Association Press: Washington DC.

Bardeen, J.R., Orcutt, H.K., 2011. Attentional control as a moderator of the relationship between posttraumatic stress symptoms and attentional threat bias. J. Anxiety Disord. 25, 10081018.

Blakemore, S. J., 2008. The social brain in adolescence. Nature Rev. Neurosci. 9, 267-277.

Brainerd, C. J., Stein, L. M., Silveira, R. A., Rohenkohl, G., Reyna, V. F., 2008. How does negative emotion cause false memories? Psychol. Sci. 19, 919-925.

Brennen, T., Dybdahl, R., Kapidzić, A., 2007. Trauma-related and neutral false memories in warinduced Posttraumatic Stress Disorder. Conscious Cogn. 16, 877-885.

Brewin, C.R., Dalgleish, T., Joseph, S., 1996. A dual representation theory of posttraumatic stress disorder. Psychol. Rev. 103, 670-686.

Brewin, C.R., Kleiner, J.S., Vasterling, J.J., Field, A.P., 2007. Memory for emotionally neutral information in posttraumatic stress disorder: A meta-analytic investigation. J. Abnorm. Psychol. 116, 448-463.

Brewin, C.R., 2011. The nature and significance of memory disturbance in posttraumatic stress disorder. Ann Rev Clin Psychol. 7, 203-227. 
Buchanan, T.W., 2007. Retrieval of emotional memories. Psychol Bull. 133, 761-779.

Burt,, D.B., Zembar, M.J., Niederehe G., 1995. Depression and memory impairment: a metaanalysis of the association, its pattern, and specificity. Psychol Bull.117, 285-305.

Cisler, J.M., Wolitzky-Taylor, K.B., Adams, T.G. Jr, Babson, K.A., Badour, C.L., Willems, J.L., 2011. The emotional Stroop task and posttraumatic stress disorder: a meta-analysis. Clin Psychol Rev. 31, 817-828.

Conway, M.A., Pleydell-Pearce, C.W., 2000. The construction of autobiographical memories in the self-memory system. Psychol. Rev. 107, 261-288.

Conway, M.A., 2001. Sensory-perceptual episodic memory and its context: autobiographical memory. Philos Trans R Soc Lond B Biol Sci. 29, 356, 1375-1384.

D'Acremont, M., Van der Linden, M., 2007. Memory for angry faces, impulsivity, and problematic behavior in adolescence. J Abnormal Child Psychol. 35, 313-324.

Elhai, J.D., Miller, M.E., Ford J.D., Biehn T.L., Palmieri P.A., Frueh B.C., 2012. Posttraumatic stress disorder in DSM-5: estimates of prevalence and symptom structure in a nonclinical sample of college students. J Anxiety Disord. 26(1), 58-64.

Estes, Z., Adelman, J. S., 2008. Automatic vigilance for negative words in lexical decision and naming: Comment on Larsen, Mercer, and Balota (2006). Emotion. 8, 441-444.

First, M.B., Spitzer, R.L., Gibbon, M., Williams, J.B.W., 1996. Structured Clinical Interview for DSM-IV axis I disorders, Clinician Version (SCID-CV). American Psychiatric 
Association Press: Washington DC.

Gallo, D.A., Foster, K.T., Johnson, E.L., 2009. Elevated false recollection of emotional pictures in young and older adults. Psychol Aging. 24, 981-988.

Galvan, A., 2010. Adolescent development of the reward system. Front Hum Neurosci. 12, 4-6.

Gardiner, J. M., 2001. Episodic memory and autonoetic consciousness: A first-person approach. Philos Trans R Soc Lond B Biol Sci. 356, 1351-1361.

Golier, J.A., Yehuda, R., Lupien, S.J., Harvey, P.D., 2003. Memory for trauma-related information in Holocaust survivors with PTSD. Psychiatry Res. 121, 133-143.

Hajcak, G., Olvet, D.M., 2008. The persistence of attention to emotion: Brain potentials during and after picture presentation. Emotion. 8, 250-255.

Hare, T.A., Tottenham, N., Galvan, A., Voss, H.U., Glover, G.H., Casey, B.J. 2008. Biological substrates of emotional reactivity and regulation in adolescence during an emotional gonogo task. Biol Psychiatry. 63, 927-934.

Howe, M.L., Courage M.L., 1997. The emergence and early development of autobiographical memory. Psychol Rev.104, 499-523.

Howe, M.L., Candel, I., Otgaar, H., Malone, C., Wimmer, M.C., 2010. Valence and the development of immediate and long-term false memory illusions. Memory. 18, 58-75.

James, W., 1890. Precis de psychologie. 10th edition, 1946. Marcel Riviere and Cie (Paris). JanetP., 1894. Histoire d'une idée fixe. Revue Philosophique, 37, 121-163.

Jelinek, L., Hottenrott, B., Randjbar, S., Peters, M.J., Moritz, S., 2009. Visual false memories in post-traumatic stress disorder (PTSD). J Behav Ther Exp Psychiatry. 40, 374-383. 
Kimble, M.O., Frueh, B.C., Marks, L., 2009. Does the modified Stroop effect exist in PTSD? Evidence from dissertation abstracts and the peer reviewed literature. J. Anxiety Disord. $23,650-655$.

Krauel, K., Duzel, E., Hinrichs, H., Rellum, T., Santel, S., Baving, L., 2009. Emotional memory in ADHD patients with and without comorbid ODD/CD. J Neural Transm. 116, 117-120.

LaBar, K. S., Cabeza, R., 2006. Cognitive neuroscience of emotional memory. Nature Rev Neurosci. 7, 54-64.

Lang, P.J., Bradley, M.M., Cuthbert, B.N., 2008. Internal affective picture system (IAPS): Affective ratings of pictures and instruction manual. Technical report A-8, University of Florida: Gainesville, FL.

Locke, J., [1690] 1975. An Essay Concerning Human Understanding. Oxford : Clarendon. 150151.

Mather, M., Sutherland, M.R., 2011. Arousal-biased competition in perception and memory. Perspect Psychol Sci. 6, 114-133.

Mickley, K. R., Kensinger, E. A., 2008. Emotional valence influences the neural correlates associated with remembering and knowing. Cogn Affect Behav Neurosci. 8, 143-152.

Moore, S.A, Zoellner, L.A., 2007. Overgeneral autobiographical memory and traumatic events: an evaluative review. Psychol Bull. 133, 419-437.

Nelson, E. E., McClure, E. B., Monk, C. S., Zarahn, E., Leibenluft, E., Pine, D. S., Ernst, M., 2003. Developmental differences in neuronal engagement during implicit encoding of emotional faces: An event-related fMRI study. J Child Psychol Psychiatry. 44, 10151024. 
Ochsner, K.N., Ray, R.R., Hughes, B., McRae, K., Cooper, J.C., Weber, J., Gabrieli, J.D., Gross, J.J., 2009. Bottom-up and top-down processes in emotion generation: common and distinct neural mechanisms. Psychol Sci. 20, 1322-1331.

Olofsson, J. K., Nordin, S., Sequeira, H., Polich, J., 2008. Affective picture processing: An integrative review of ERP findings. Biol Psycho. 77, 247-265.

Pineles, S.L., Shipherd, J.C., Welch, L.P., Yovel, I. 2007. The role of attentional biases in PTSD: is it interference or facilitation? Behav Res Ther. 45, 1903-1913.

Rimmele, U., Davachi, L., Petrov, R., Dougal, S., Phelps, E.A., 2011. Emotion enhances the subjective feeling of remembering, despite lower accuracy for contextual details. Emotion. 11, 553-562.

Ritchey, M., LaBar, K.S., Cabeza, R., 2011. Level of processing modulates the neural correlates of emotional memory formation. J Cogn Neurosci. 23, 757-771.

Schacter, D.L., Gallo, D.A., Kensinger, E.A., 2007. The cognitive neuroscience of implicit and false memories: Perspectives on processing specificity. In: Nairne, J.S. (Ed.), The foundations of remembering: Essays in honor of Henry L. Roediger, 3rd edition. Psychology Press: New York, pp. 353-377.

Schimmack, U., Derryberry, D., 2005. Attentional interference effects of emotional pictures: Threat, negativity, or arousal? Emotion. 5, 55-66.

St Jacques, P.L., Botzung, A., Miles, A., Rubin, D.C., 2011. Functional neuroimaging of emotionally intense autobiographical memories in post-traumatic stress disorder. J Psychiatr Res. 45, 630-637. 
Sundin, E.C., Horowitz, M.J., 2002. Impact of Event Scale: psychometric properties. Br J Psychiatry. 180, 205-209.

Talmi, D., Anderson, A. K., Riggs, L., Caplan, J. B., Moscovitch, M., 2008. Immediate memory consequences of the effect of emotion on attention to pictures. Learn Mem. 15, 172-182.

Tulving, E., 1972. Episodic and semantic distinction. In: Tulving, E., Donaldson W. (Eds.), Organization of memory. Academic Press (New York), pp.381-403.

Tulving, E., 2002. Episodic Memory: from mind to brain. Ann Rev Psychol. 53, 1-25.

Tulving, E., 2005. Episodic memory and autonoesis: Uniquely human? In: Terrace, H. S., Metcalfe, J. (Eds.), The Missing Link in Cognition. Oxford University Press (New York), pp. 4-56.

Van der Kolk, B.A., Fisler, R., 1995. Dissociation and the fragmentary nature of traumatic memories: overview and exploratory study. J Trauma Stress. 8, 505-525.

Van der Kolk, B.A., 2006. Clinical implications of neuroscience research in PTSD. Ann N Y Acad Sci. 1071, 277-293.

Wang, L., Huettel, S., De Bellis, M. D., 2008. Neural substrates for processing task-irrelevant sad images in adolescents. Dev Sci. 11, 23-32.

Wechsler, D., 1996. Echelle d'intelligence de Wechsler pour enfants et adolescents. 3rd edition. Les Editions du Centre de Psychologie Appliquée (Paris).

Wechsler, D., 2000. Wais III. 3rd edition. Les Editions du Centre de Psychologie Appliquée (Paris). 
Wells, H.G., 1898/2002. The Time Machine. New York: The Modern Library, 2002.

Williams, J.M., Barnhofer, T., Crane, C., Herman, D., Raes, F., Watkins, E., Dalgleish, T., 2007. Autobiographical memory specificity and emotional disorder. Psychol Bull. 133, 122-148.

Wilson, A.E., Ross M., 2003. The identity function of autobiographical memory: time is on our side. Memory. 11,137-49.

Yang, P., Wu, M.T., Hsu, C.C., Ker, J.H., 2004. Evidence of early neurobiological alternations in adolescents with posttraumatic stress disorder: a functional MRI study. Neurosci Lett. $370,13-18$.

Yiend, J., 2010. .The effects of emotion on attention: A review of attentional processing of emotional information Cognition \& Emotion, 24, 3-47.

Yurgelun-Todd, D., 2007. Emotional and cognitive changes during adolescence. Curr Opin Neurobiol. 17, 251-257. 


\section{Figure Legends}

Fig.1. Schematic illustration of the experimental design depicting the three types of stimulus scenes and two memory phases. Targets scenes are presented during the oddball paradigm and during the recognition task mingled with new unstudied controls.

Fig.2. Changes in RTs (ratio) for neutral, negative conceptual and negative perceptual scenes, compared to the reference conditions in the oddball paradigm (mean $\pm \mathrm{SD})$.

Fig. 3. Changes in RTs (ratio) in the three groups of adolescents for neutral, negative conceptual and negative perceptual scenes, compared to the reference conditions in the oddball paradigm $($ mean $\pm \mathrm{SD})$. 
Table 1

Mean $( \pm \mathrm{SD})$ performances of typically developing adolescents on the recognition task.

\begin{tabular}{lllll}
\hline & Hits & & Recollection & Familiarity \\
\hline & Targets (\%) & Distractors (\%) & & \\
\hline Neutral & $94.25(7.68)$ & $98.13(4.14)$ & $0.53(0.33)$ & $0.62(0.39)$ \\
Negative conceptual & $95.86(6.50)$ & $86.90(8.20)$ & $0.59(0.29)$ & $0.65(0.40)$ \\
Negative perceptual & $95.51(9.02)$ & $94.65(7.54)$ & $0.65(0.28)$ & $0.60(0.43)$ \\
\hline
\end{tabular}




\section{Table 2a}

Mean $( \pm \mathrm{SD})$ performances on the recognition task for the two subgroups of patients and controls.

\begin{tabular}{|c|c|c|c|c|}
\hline & Controls (\%) & PTSD + & PTSD- & $\begin{array}{l}\text { Statistical } \\
\text { Comparisons }\end{array}$ \\
\hline \multicolumn{5}{|l|}{ Targets $(\%)$} \\
\hline Neutral & $91.67(11.78)$ & $92.94(10.11)$ & $80.55(22.57)$ & \\
\hline Negative conceptual & $97.50(4.42)$ & $96.92(4.80)$ & $88.33(18)$ & \\
\hline Negative perceptual & $95(7.22)$ & $97.69(4.38)$ & $86.67(13.7)$ & PTSD-<controls \\
\hline \multicolumn{5}{|l|}{ Distractors (\%) } \\
\hline Neutral & $99.30(2.35)$ & $98.71(3.13)$ & $97.91(3.77)$ & \\
\hline Negative conceptual & $87.91(7.21)$ & $85.38(11.98)$ & $81.67(11.15)$ & PTSD-<controls \\
\hline Negative perceptual & $96.25(5.76)$ & $96.15(6.5)$ & $91.67(10.3)$ & \\
\hline
\end{tabular}




\section{Table 2b}

Mean $( \pm \mathrm{SD})$ performances on the recollection and familiarity judgments for the two subgroups of patients and controls.

\begin{tabular}{lcccc}
\hline & Controls (\%) & PTSD + & PTSD- & $\begin{array}{l}\text { Statistical } \\
\text { Comparisons }\end{array}$ \\
\hline Recollection & & & & \\
\hline Neutral & $0.52(0.37)$ & $0.63(0.29)$ & $0.39(0.40)$ & \\
Negative conceptual & $0.68(0.26)$ & $0.73(0.16)$ & $0.50(0.20)$ & PTSD-<controls \\
Negative perceptual & $0.68(0.29)$ & $0.72(0.20)$ & $0.58(0.37)$ & PTSD-<controls \\
\hline Familiarity & & & & \\
\hline Neutral & $0.52(0.39)$ & $0.52(0.37)$ & $0.39(0.40)$ & \\
Negative conceptual & $0.55(0.43)$ & $0.62(0.41)$ & $0.74(0.28)$ & \\
Negative perceptual & $0.50(0.42)$ & $0.51(0.44)$ & $0.58(0.37)$ & \\
& & & & \\
\hline
\end{tabular}




\section{Stimulus type}

Neutral

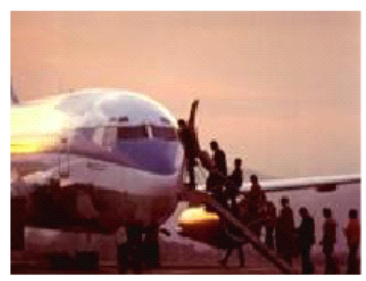

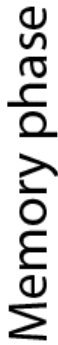

Encoding phase

(Oddball paradigm)

Explicit memory

(Recognition task)

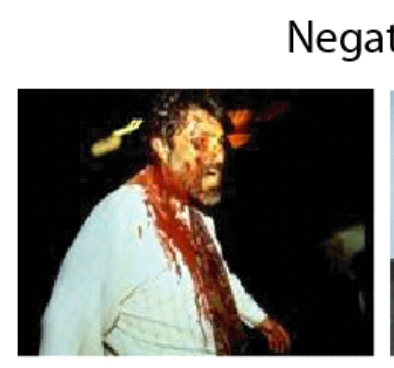

Instructions

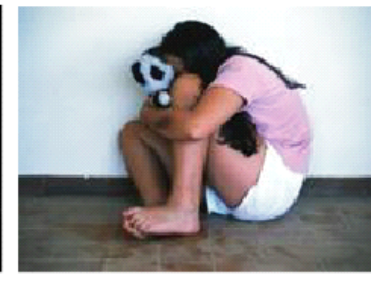

Categorize images as real scenes or geometric figures

Targets / Geometric figures

Recognize targets from controls

Recollection/ Familiarity

Studied targets / non-studied controls 


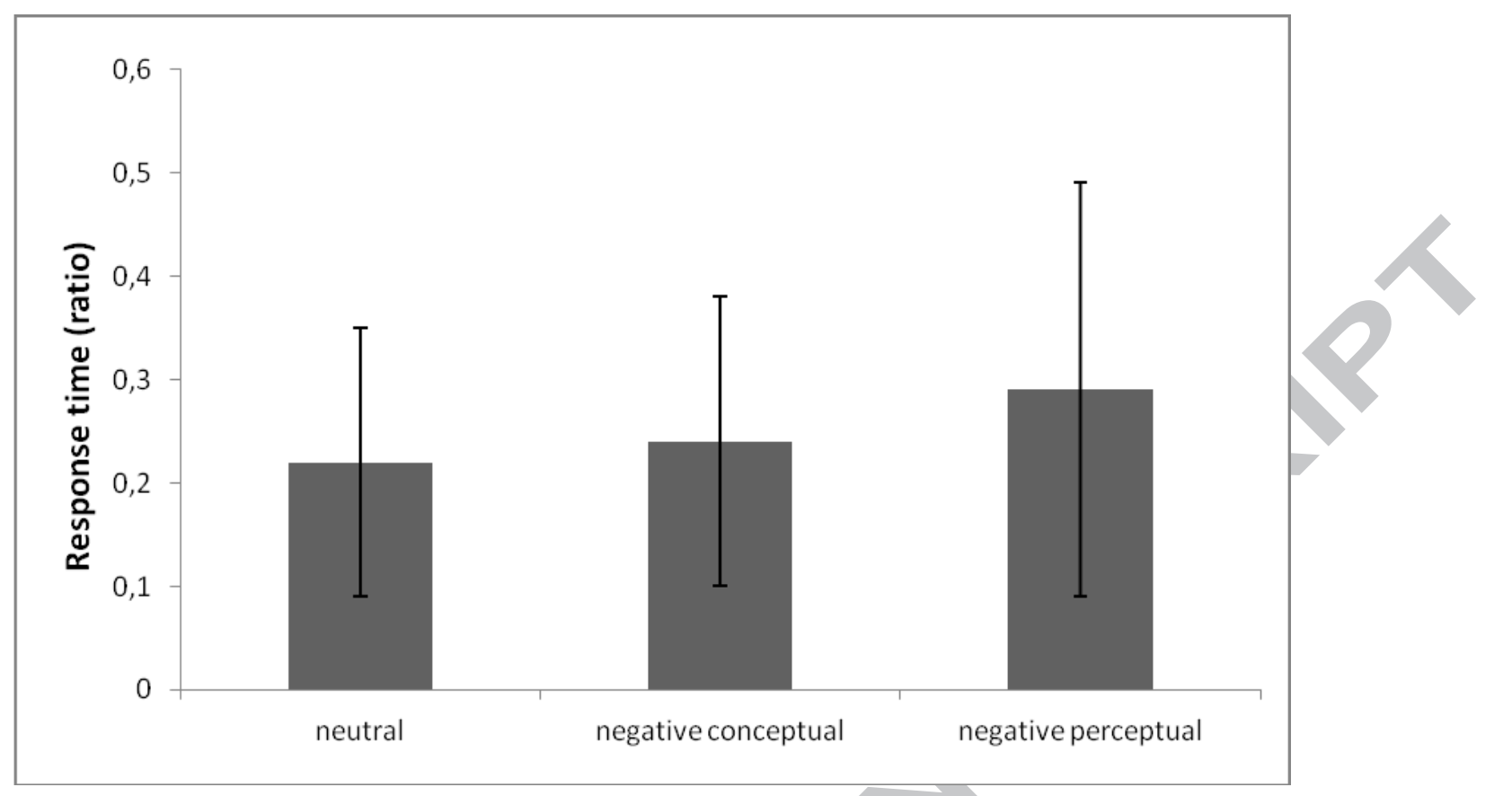




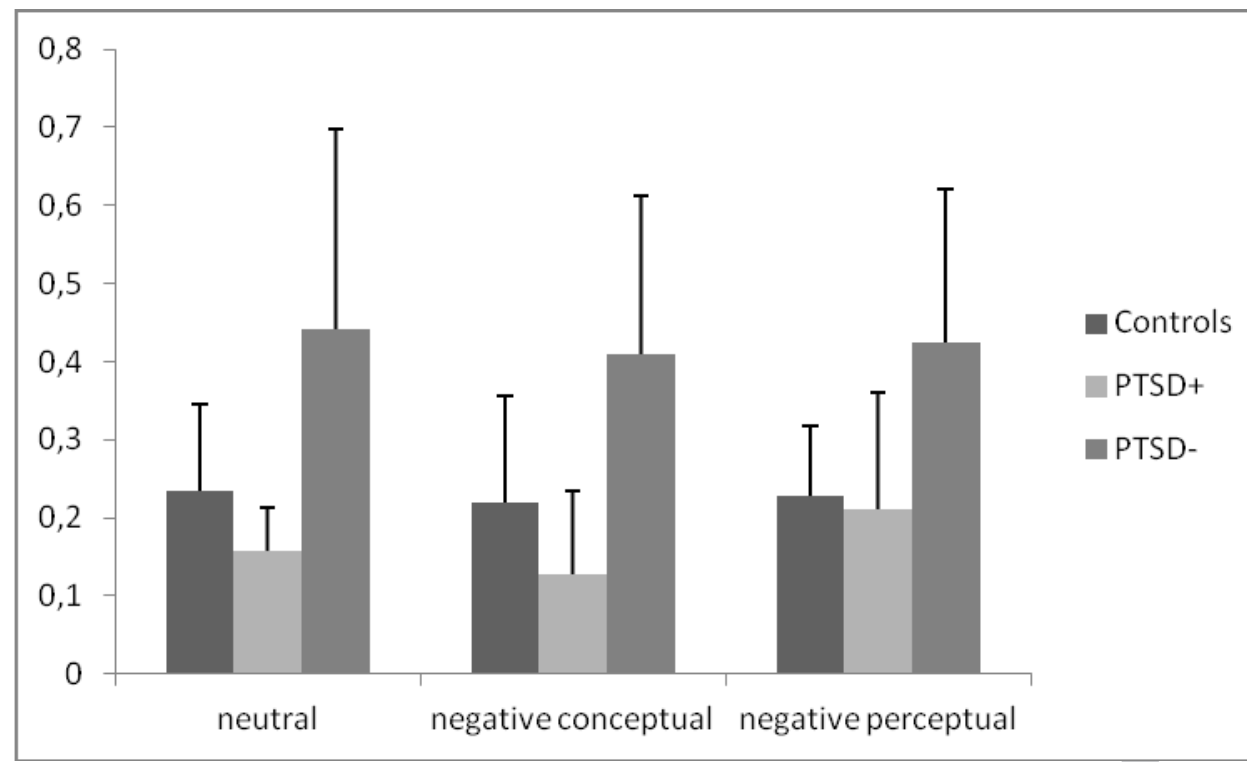

